\title{
Effects of Nitrogen Dilution on the Photoresist Removal Rate by Hydrogen Radicals
}

\author{
Masashi Yamamoto ${ }^{1 *}$, Hiroto Nishioka ${ }^{1}$, Koki Akita ${ }^{1}$, Shiro Nagaoka ${ }^{2}$, \\ Hironobu Umemoto ${ }^{3,4}$, and Hideo Horibe ${ }^{4}$ \\ ${ }^{1}$ Department of Electrical and Computer Engineering, National Institute of Technology, \\ Kagawa College, 355 Chokushi-cho, Takamatsu, Kagawa 761-8058, Japan \\ ${ }^{2}$ Department of Electronic Systems Engineering, National Institute of Technology, \\ Kagawa College, 551 Kohda, Takuma-cho, Mitoyo, Kagawa 769-1192, Japan \\ ${ }^{3}$ Shizuoka University, Johoku, Naka, Hamamatsu, Shizuoka 432-8561, Japan \\ ${ }^{4}$ Department of Applied Chemistry and Bioengineering, Graduate School of Engineering, \\ Osaka City University, 3-3-138, Sugimoto-cho, Sumiyoshi, Osaka 558-8585, Japan \\ *m-yamamoto@t.kagawa-nct.ac.jp
}

\begin{abstract}
We have previously demonstrated that photoresist removal rate comparable to oxygen plasma is accomplished by optimizing the removal conditions with $\mathrm{H}$ radicals produced on hot metal filament surfaces from $\mathrm{H}_{2} / \mathrm{N}_{2}$ mixtures $\left(\mathrm{H}_{2}: \mathrm{N}_{2}=10: 90 \mathrm{vol} \%\right)$. $\mathrm{N}_{2}$ gas was used to dilute the concentration of the $\mathrm{H}_{2}$ gas and to reduce the risk of explosion. However, it is not clear how the dilution of $\mathrm{H}_{2}$ by $\mathrm{N}_{2}$ affects the removal rate. In this paper, we examined the relationship between the removal rate and the $\mathrm{H}_{2}$ content; the flow rate ratio of $\mathrm{H}_{2}$ to $\mathrm{H}_{2}+\mathrm{N}_{2}$. The removal rate increased with increasing the $\mathrm{H}_{2}$ content. In addition, the removal rate increased with increasing the substrate temperature according to an Arrhenius equation, when the $\mathrm{H}_{2}$ content was over $90 \%$. However, below $60 \%$, the removal rate decreased with increasing the temperature over $230 \pm 5{ }^{\circ} \mathrm{C}$. Denaturation of photoresist, e.g. hardening and/or crosslinking, may be induced by substrate heating when the $\mathrm{H}$-radical density is low. The removal rate decreases not only by the deficiency of $\mathrm{H}$ radicals but also by the denaturation of films in $\mathrm{H}_{2} / \mathrm{N}_{2}$ mixed systems.
\end{abstract}

Keywords: Photoresist, Decomposition, $\mathrm{H}$ Radical, $\mathrm{H}_{2} / \mathbf{N}_{2}$ mixture

\section{Introduction}

Photoresists are indispensable materials for fabricating fine patterns on the substrate in microand nano-electronics device manufacturing. The role of photoresist is to protect the predetermined area from some processes, e.g. deposition, etching, and ion implantation. In general, photoresists must be removed for the next step. Chemicals, which are hazardous to humans and the environment, are often used to remove photoresists $[1,2]$. There are several problems such as environmental impacts and costs of chemicals in photoresist removal, because an enormous amount of chemicals is necessary to shorten the batch process times.

To overcome the above issues, we have examined a way of photoresist removal using $\mathrm{H}$ radicals $[3,4]$. $\mathrm{H}$ radicals can be produced by decomposing molecular $\mathrm{H}_{2}$ on metal hot filament surfaces [5-7]. Our earlier study demonstrated that the removal rate comparable to oxygen plasma is accomplished by optimizing the removal conditions in $\mathrm{H}_{2} / \mathrm{N}_{2}$ mixed systems $\left(\mathrm{H}_{2}: \mathrm{N}_{2}=10: 90 \mathrm{vol} \%\right)$ [3]. $\mathrm{N}_{2}$ gas was used to dilute the concentration of the $\mathrm{H}_{2}$ gas and to reduce the risk of explosion. However, the relationship between the removal rate and the dilution ratio has not been examined enough. In this paper, we show the effect of the dilution on the removal rate in $\mathrm{H}_{2} / \mathrm{N}_{2}$ mixed systems.

\section{Experimental}

The experiment apparatus and the procedure were similar to those described elsewhere [8-12]. The $\mathrm{H}_{2}$ gas $(\geq 99.99 \%$; Takamatsu Teisan Co.) flow rate was varied between 0 and $50 \mathrm{sccm}$ using a mass 
flow controller (PE-D20; HORIBA STEC). The $\mathrm{N}_{2}$ gas ( $\geq 99.995 \%$; Takamatsu Teisan Co.) flow rate was also varied between 0 and $50 \mathrm{sccm}$ using another mass flow controller (PE-D20; HORIBA STEC). The $\mathrm{H}_{2}$ content, the dilution ratio by $\mathrm{N}_{2}$, was calculated by dividing $\mathrm{H}_{2}$ flow rate by $\mathrm{H}_{2}+\mathrm{N}_{2}$ flow rate. This content was varied between 0 and $100 \%$. The typical total pressure under processing was 2.7 $\mathrm{kPa}$, as measured using a vacuum gauge (Baratron 622A12TAE; MKS Instruments Inc.).

As a hot filament catalyst, a resistively heated iridium wire $(99.9 \%, 0.5 \mathrm{~mm}$ diameter, $500 \mathrm{~mm}$ long; Tanaka Precious Metals) was used: it was coiled with 11 turns, with respective coil length and diameter of $40 \mathrm{~mm}$ and $8 \mathrm{~mm}$. The distance between the catalyst and the substrate was $20 \mathrm{~mm}$. A DC power supply (EX-750L2; Takasago Ltd.) was used to heat the catalyst. The catalyst temperature $\left(T_{\mathrm{C}}\right)$ at the central position, which was measured through a quartz window using a two-wavelength $(0.80$ and $1.05 \mu \mathrm{m})$ infrared radiation thermometer, was 1670 $\pm 10^{\circ} \mathrm{C}$. Table 1 shows the relationship between DC power and $T_{\mathrm{C}}$ in various $\mathrm{H}_{2}$ content atmosphere.

Table 1. The relationship between DC power and $T_{\mathrm{C}}$ in various $\mathrm{H}_{2}$ content atmosphere.

\begin{tabular}{ccc}
\hline \hline $\mathrm{H}_{2}$ content $[\%]$ & DC power $[\mathrm{W}]$ & $T_{\mathrm{C}}\left[{ }^{\circ} \mathrm{C}\right]$ \\
\hline 100 & 169 & 1669 \\
90 & 163 & 1669 \\
80 & 150 & 1670 \\
60 & 130 & 1670 \\
40 & 116 & 1672 \\
20 & 100 & 1670 \\
10 & 96 & 1671 \\
0 & 91 & 1670 \\
\hline \hline
\end{tabular}

A positive-tone novolak photoresist (OFPR-800; Tokyo Ohka Kogyo) was used in this study. It was spin-coated onto a Si wafer using a spin coater (K$359 \mathrm{~S}-1$; Kyowariken) at $2.6 \times 10^{3} \mathrm{rpm}$ for $20 \mathrm{~s}$ and was prebaked in an oven (CLO-2AH; Koyo Thermo Systems) at $100{ }^{\circ} \mathrm{C}$ for $60 \mathrm{~s}$. The initial photoresist film thickness was $1.2 \mu \mathrm{m}$, which was measured using a surface texture measuring instrument (Surfcom 480A; Tokyo Seimitsu).

Changes in film thickness were evaluated using thin film interference of the photoresist [8]. By thin film interference, the peaks and valleys of the reflected light intensity were observed alternately during changes in film thickness. The film thickness can be calculated from the reflected light intensity. Green laser light from the optical source $(520 \mathrm{~nm}$, $150 \mathrm{~mW}$; CivilLaser, Naku Technology Co. Ltd.) entered the center of the stage at an incident angle against the substrate surface of $76^{\circ}$. A Si photodiode (S1787-04; Hamamatsu Photonics K.K.) in reverse bias was used as a photodetector to measure the whether or not intensity of light reflected from the substrate. Its cathode was connected to $+5 \mathrm{~V}$ DC through a $60 \mathrm{k} \Omega$ resistor. The reflected light intensity was ascertained by calibrating the voltage between both ends of the resistor.

We heated the substrate using a substrate stage heater to evaluate the dependence of the removal rate on the substrate surface temperature $\left(T_{\text {surf }}\right)$. A sheath thermocouple (TK $\varphi 1.6 \times \mathrm{L} 300$; As One) was used for the surface temperature measurement. The thermocouple was placed on the substrate surface, $20 \mathrm{~mm}$ distant from the stage center. Initial $T_{\text {surf }}$ was $25{ }^{\circ} \mathrm{C}$. Averaged rate of $T_{\text {surf }}$ increase was 8.2 ${ }^{\circ} \mathrm{C} / \mathrm{min}$. $T_{\text {surf }}$ must be determined by some factors, such as not only the stage heater but also the radiation heat, when the Ir filament is heated. The temperature and film thickness were measured simultaneously at $0.2 \mathrm{~s}$ intervals. The removal rate was calculated from the average during $2 \mathrm{~s}$.

\section{Results and discussion}

Figure 1 shows the removal rate of novolak photoresist as a function of the substrate surface temperature in pure $\mathrm{H}_{2}$ or $\mathrm{N}_{2}$ atmosphere. Strictly speaking, the vertical axis of Fig. 1 is the decrease rate in film thickness, which includes the rates of not only removal by decomposition but also thermal shrinkage. However, just for simplicity, we would like to call removal rate. When heating the filament in $\mathrm{H}_{2}$ atmosphere, the removal rate increased drastically. This can easily be attributed to the removal by $\mathrm{H}$ radicals produced from $\mathrm{H}_{2}$. The

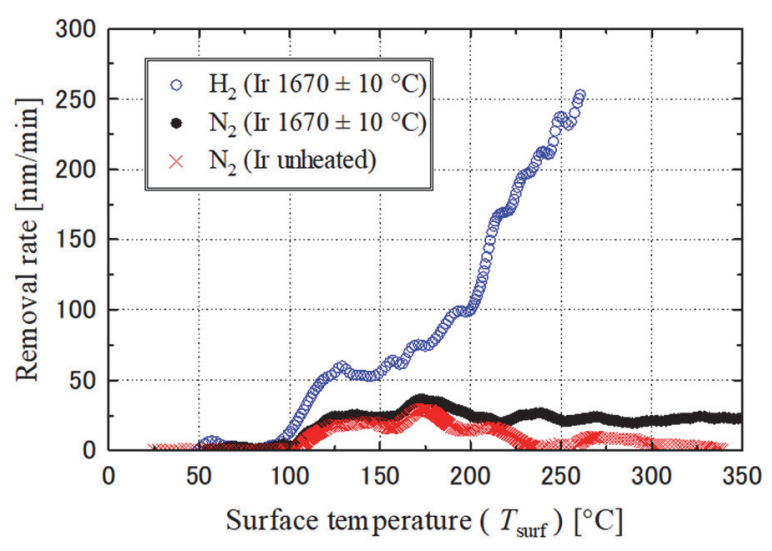

Fig. 1. Removal rate of novolak photoresist as a function of the substrate surface temperature in $\mathrm{H}_{2}$ or $\mathrm{N}_{2}$ atmosphere. 
substrate temperature dependence was Arrheniuslike, which is consistent with our former observation [13,14]. In $\mathrm{N}_{2}$ atmosphere, on the other hand, the substrate temperature dependence is less remarkable. The production of $\mathrm{N}$ radicals on hot filament surfaces is inefficient, as will be discussed below $[15,16]$. The decomposition of polymers by $\mathrm{N}$ radicals cannot be expected.

In $\mathrm{N}_{2}$ atmospheres, although small, decrease in film thickness could be observed even when the filament was not heated. This should be attributed to the shrinkage of photoresist. Pyrolysis must be minor below $350{ }^{\circ} \mathrm{C}$ because of the heat resistance of photoresist, which is mainly composed of a phenol resin [17]. The shrinkage at the temperature of $100-150{ }^{\circ} \mathrm{C}$ must be caused by volatilization of the solvent, which is remaining in the photoresist film. Boiling point of propylene glycol monomethyl ether acetate, which is commonly used for the solvent, is $146{ }^{\circ} \mathrm{C}$ under standard atmospheric pressure. This boiling point, of course, decreases under low pressures. Shrinkage may also be caused by the thermal hardening and crosslinking. Our earlier study shows that the photoresist is hardened thermally and its removal rate decreases with increasing baking temperature in air [18]. The hardening and/or crosslinking may take place.

From the data when the Ir filament was unheated, we can determine the shrinkage rate. Our earlier study shows that the shrinkage almost saturates within $1 \mathrm{~min}$ at temperatures lower than $250{ }^{\circ} \mathrm{C}$ and increases with increasing the baking temperature in air [3]. The decrease in the film thickness for $1 \mathrm{~min}$ at $250{ }^{\circ} \mathrm{C}$ was $0.24 \mu \mathrm{m}$ (decrease ratio $20 \%$ ) and then the film remained constant in thickness even when baking for $60 \mathrm{~min}$. When the temperature reached $250{ }^{\circ} \mathrm{C}$ under $\mathrm{N}_{2}$ atmosphere (Fig. 1), the decrease without a hot filament was $0.18 \mu \mathrm{m}(18 \%)$. Therefore, the decrease must be ascribed to the shrinkage of the photoresist film since the decrease ratio was similar.

Although minor, the decrease rate in thickness is larger when the filament is heated in $\mathrm{N}_{2}$ atmosphere. It is possible to produce $\mathrm{N}$ radicals from $\mathrm{N}_{2}$ on a hot catalyst without coproducing other active species. The density has been measured to be $1.2 \times 10^{11} \mathrm{~cm}^{-3}$ when the $\mathrm{W}$ filament temperature is $2.8 \times 10^{3} \mathrm{~K}$ and the $\mathrm{N}_{2}$ pressure is $100 \mathrm{~Pa}[15,16]$. At $2.0 \times 10^{3} \mathrm{~K}$, the density is estimated to be $3 \times 10^{7} \mathrm{~cm}^{-3}$. This value is negligibly small compared to the typical density of $\mathrm{H}$ radicals, $10^{14} \mathrm{~cm}^{-3}$ at $2.0 \times 10^{3} \mathrm{~K}$ [19]. The situation must be similar when Ir is used instead of W. N radicals $(\mathrm{N} \bullet)$ cannot be obtained by the gas- phase reaction between $\mathrm{N}_{2}$ and an $\mathrm{H}$ radical $(\mathrm{H} \bullet) ; \mathrm{N}_{2}$ $+\mathrm{H} \bullet \rightarrow \mathrm{NH}+\mathrm{N} \bullet$, either. This reaction is too endothermic to take place [20]. Therefore, we may conclude that $\mathrm{N}$ radicals cannot influence on the photoresist removal.

Even in pure $\mathrm{N}_{2}$ atmosphere, when the filament is heated, photoresist may be decomposed by radicals, including $\mathrm{H}$ radicals, which are produced by catalytic decomposition of volatiles effused from photoresists. One of the candidates of such volatiles is the solvent for polymers. Another possibility is the shrinkage of photoresist film induced by heat radiation from the hot filament. These can be regarded as the factor of the increase in the removal rate. Incidentally, in air, the decrease for $1 \mathrm{~min}$ at $350{ }^{\circ} \mathrm{C}$ was $0.35 \mu \mathrm{m}$ (decrease ratio $29 \%$ ) and then the film thickness decreased at the rate of about 20 $\mathrm{nm} / \mathrm{min}$ for $9 \mathrm{~min}(45 \%)$ [3]. The thickness decreased at the rate of about $4 \mathrm{~nm} / \mathrm{min}$ from $10 \mathrm{~min}$ to at least $60 \mathrm{~min}(60 \%$ at $60 \mathrm{~min})$. This rate was probably caused by the decomposition but very small. This small rate should be ascribed to the enhancement of the heat resistance on photoresist by the thermal hardening and crosslinking [18]. In Fig. 1, the decrease in the film thickness, when the temperature reached $350{ }^{\circ} \mathrm{C}$ using heated $\mathrm{Ir}$ under $\mathrm{N}_{2}$ atmosphere, was $0.64 \mu \mathrm{m}$; the decrease ratio of the film thickness was $66 \%$. The time the temperature takes to reach that temperature was $32.8 \mathrm{~min}$. The decrease ratio in Ref [3] corresponding to this condition is about $52 \%$ and is $14 \%$ lower than that using heated Ir. On the other hand, when using unheated Ir, the temperature reached $340{ }^{\circ} \mathrm{C}$ at $38.1 \mathrm{~min}$. The decrease in the film thickness was $0.27 \mu \mathrm{m}(27 \%)$. Even if the temperature was $350{ }^{\circ} \mathrm{C}$, the decrease must not be too different. The decrease ratio in Ref [3] is about $57 \%$ and is $30 \%$ larger than that using unheated Ir. The thermal hardening and crosslinking should be regarded as the factor of the decrease in the removal rate since they can cause this small decrease ratio. The decomposition and the hardening can simultaneously take place when using a hot filament. All of them are fortuitously balanced, so the removal rate might become constant against the substrate surface temperature. We will discuss this possibility later.

Figure 2 shows the removal rate of novolak photoresist as a function of the substrate surface temperature in $\mathrm{H}_{2} / \mathrm{N}_{2}$ mixtures. Here, as is the case for Fig. 1, removal is used to present both decomposition and shrinkage. $\mathrm{H}_{2}$ content is the flow rate ratio of $\mathrm{H}_{2}$ to $\mathrm{H}_{2}+\mathrm{N}_{2}$. The removal rate 
decreased with decreasing in $\mathrm{H}_{2}$ content, as expected, but the removal rate at $\mathrm{H}_{2}$ content of $90 \%$ was very similar to that in the pure $\mathrm{H}_{2}$ system. Both removal rates increased with increasing the substrate temperature, according to an Arrhenius equation. Therefore, the dilution by $\mathrm{N}_{2}$ might not influence on the photoresist removal at these contents. Remarkably, when $\mathrm{H}_{2}$ content was between 10 and $60 \%$, the removal rates increased with increasing the temperature up to $230 \pm 5{ }^{\circ} \mathrm{C}$, but decreased over that temperature.

The decrease in removal rate is to be expected when decreasing $\mathrm{H}_{2}$ content, because the population of $\mathrm{H}$ radicals must decrease with decreasing that of $\mathrm{H}_{2}$. The problem is the substrate surface temperature dependence at low $\mathrm{H}_{2}$ contents. The temperature of $230 \pm 5{ }^{\circ} \mathrm{C}$, at which the change in slope of the plot is observed, may be related to hardening and/or crosslinking onset temperature of photoresist polymer. Base polymer of novolak photoresists has benzene rings in its main chain. The reaction between benzene rings and $\mathrm{H}$ radicals must be the rate-determining step in the removal processes [13, 14]. According to the theoretical approach by Umemoto et al. [21], at least two H radicals must be involved in the decomposition of novolak. After the addition of two $\mathrm{H}$ radicals to the benzene ring, the ring opening becomes energetically possible. Polymer chains can be decomposed continuously rather than hardening and crosslinking if the population of $\mathrm{H}$ radical is enough. However, if $\mathrm{H}$ radical is deficient, polymer is activated insufficiently to produce some active sites, which cannot be starting points of decomposition. These

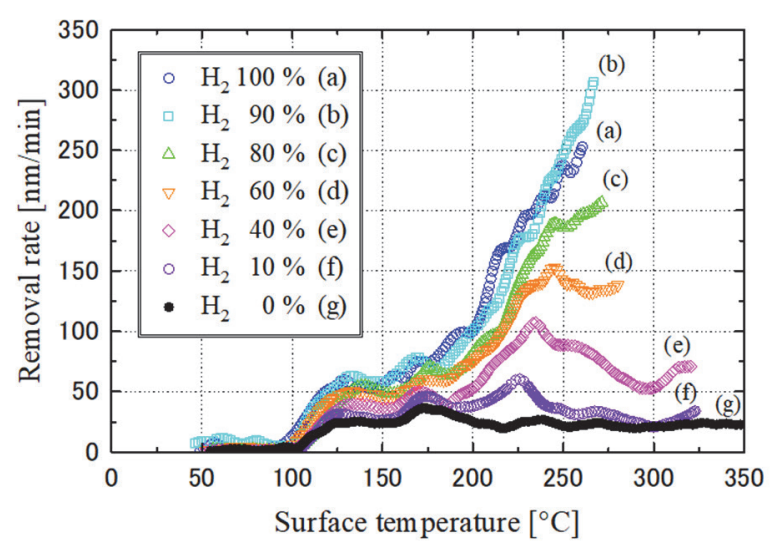

Fig. 2. Removal rate of novolak photoresist as a function of the substrate surface temperature in $\mathrm{H}_{2} / \mathrm{N}_{2}$ mixtures. $\mathrm{H}_{2}$ content is the flow rate ratio of $\mathrm{H}_{2}$ to $\mathrm{H}_{2}+\mathrm{N}_{2}$. $T_{\mathrm{C}}$ was heated to $1670 \pm 10^{\circ} \mathrm{C}$. active sites may be able to bind each other at high substrate temperatures and the decomposition is prevented.

Figure 3 shows the removal rate of novolak photoresist as a function of the square root of the partial pressure of $\mathrm{H}_{2}$. The removal rate increases in direct proportion to the H-radical density and its density increases in direct proportion to the square root of $\mathrm{H}_{2}$ pressure $[13,19]$. Namely, the removal rate must bear a direct relation to the square root of $\mathrm{H}_{2}$ pressure. At the temperature of $200{ }^{\circ} \mathrm{C}$ and $225^{\circ} \mathrm{C}$, we confirmed the proportional relationship between the removal rate and the square root of the $\mathrm{H}_{2}$ pressure, predictably. The $\mathrm{H}$ radical density would be enough to decompose photoresist at these temperatures. However, at $250{ }^{\circ} \mathrm{C}$, the removal rate bore a non-linear relationship with the square root of $\mathrm{H}_{2}$ pressure. As shown in Fig. 2, the proportional relationship should be true at $\mathrm{H}_{2}$ content of 90 and $100 \%$ because these removal rates obeyed the Arrhenius equation. Accordingly, we consider that the dashed line connecting the plots (a), (b), and (c), shown in Fig. 3, is proper relationship. The removal rate becomes smaller than the expected when the square root of $\mathrm{H}_{2}$ pressure is between 0.51 and 1.46 $\mathrm{kPa}^{1 / 2}$. This decrease may be ascribed not only to the decrease in $\mathrm{H}$ radical density but also to the denaturation of photoresist.

\section{Conclusion}

In this study, we examined the relationship between the removal rate and the $\mathrm{H}_{2}$ content, which is the flow rate ratio of $\mathrm{H}_{2}$ to $\mathrm{H}_{2}+\mathrm{N}_{2}$. The removal rate increased with increasing in the $\mathrm{H}_{2}$ content. The

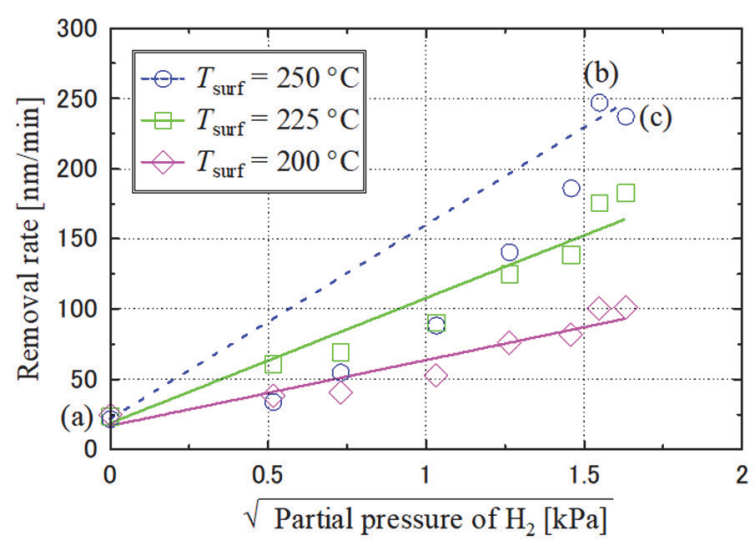

Fig. 3. Removal rate of novolak photoresist as a function of the square root of partial pressure of $\mathrm{H}_{2} . T_{\mathrm{C}}$ was 1670 $\pm 10{ }^{\circ} \mathrm{C}$. The partial pressure was calculated by multiplying $\mathrm{H}_{2}$ content by the typical total pressure. 
removal rate in pure $\mathrm{N}_{2}$ systems was much smaller than that in pure $\mathrm{H}_{2}$ systems, when using a hot filament. We confirmed that $\mathrm{N}$ radicals do not influence on the photoresist removal.

The removal rate saturated when the $\mathrm{H}_{2}$ content was more than $90 \%$. The $\mathrm{H}$ radical density would be enough to decompose photoresist at these contents. Under such conditions, the removal rates increased with increasing the substrate temperature, according to an Arrhenius equation.

When $\mathrm{H}_{2}$ content was between 10 and $60 \%$, the removal rate decreased with the increase in the substrate surface temperature over $230 \pm 5{ }^{\circ} \mathrm{C} . \mathrm{H}$ radicals must become deficient due to the decrease in the $\mathrm{H}_{2}$ content. Denaturation of photoresist, e.g. hardening and/or crosslinking, may perhaps be induced by the increase in the temperature and the deficiency in $\mathrm{H}$ radicals.

We have previously accomplished the removal rate comparable to oxygen plasma in $\mathrm{H}_{2} / \mathrm{N}_{2}$ mixed systems, with the $\mathrm{H}_{2}$ content of $10 \%$. The removal rate may increase more at higher $\mathrm{H}_{2}$ contents, such as more than $90 \%$. On the other hand, content below $10 \%$ is desired to reduce the risk of explosion of exhaust gas. Both requirements, high removal rate and safety, can be satisfied by keeping the low pressure and high contents in the process chamber and by diluting the exhaust gas at the exit-side.

\section{Acknowledgement}

This work was supported by JSPS KAKENHI Grant Number 19K04543.

\section{References}

1. H. Morinaga, T. Futatsuki, T. Ohmi, E. Fuchita, M. Oda, and C. Hayashi, J. Electrochem. Soc., 142 (1995) 966.

2. K. Hirose, H. Shimada, S. Shimomura, M. Onodera, and T. Ohmi, J. Electrochem. Soc., 141 (1994) 192.

3. M. Yamamoto, H. Horibe, H. Umemoto, K. Takao, E. Kusano, M. Kase, and S. Tagawa, Jpn. J. Appl. Phys., 48 (2009) 026503.

4. M. Yamamoto, H. Umemoto, K. Ohdaira, S. Nagaoka, T. Shikama, T. Nishiyama, and H. Horibe, J. Photopolym. Sci. Technol., 28 (2015) 303.
5. H. Umemoto and M. Moridera, J. Appl. Phys., 103 (2008) 034905.

6. T. W. Hickmott, J. Chem. Phys., 32 (1960) 810.

7. J. N. Smith, Jr. and W. L. Fite, J. Chem. Phys., 37 (1962) 898.

8. M. Yamamoto, H. Umemoto, K. Ohdaira, T. Shikama, T. Nishiyama, and H. Horibe, Jpn. J. Appl. Phys., 55 (2016) 076503.

9. M. Yamamoto, K. Maejima, H. Umemoto, K. Ohdaira, T. Shikama, T. Nishiyama, and H. Horibe, J. Photopolym. Sci. Technol., 29 (2016) 639.

10. M. Yamamoto, T. Taki, T. Sunada, T. Shikama, S. Nagaoka, H. Umemoto, and H. Horibe, J. Photopolym. Sci. Technol., 31 (2018) 419.

11. M. Yamamoto, T. Shiroi, T. Shikama, S. Nagaoka, H. Umemoto, and H. Horibe, $J$. Photopolym. Sci. Technol., 32 (2019) 609.

12. M. Yamamoto, S. Nagaoka, H. Umemoto, K. Ohdaira, T. Nishiyama, and H. Horibe, Int. J. Polym. Sci., 2017 (2017) 2983042.

13. M. Yamamoto, T. Maruoka, A. Kono, H. Horibe, and H. Umemoto, Appl. Phys. Express, 3 (2010) 026501.

14. M. Yamamoto, T. Maruoka, A. Kono, H. Horibe, and H. Umemoto, Jpn. J. Appl. Phys., 49 (2010) 016701.

15. H. Umemoto, Appl. Phys. Express, 3 (2010) 076701.

16. H. Umemoto, T. Funae, and Y. A. Mankelevich, J. Phys. Chem. C, 115 (2011) 6748.

17. Ed. Osaka Municipal Technical Research Institute and Japan Society of Plastics Technology, "Plastic Dokuhon", Plastic Age, Tokyo, 1985, 14th ed (in Japanese).

18. T. Maruoka, Y. Goto, M. Yamamoto, H. Horibe, E. Kusano, K. Takao, and S. Tagawa, J. Photopolym. Sci. Technol., 22 (2009) 325.

19. H. Umemoto, K. Ohara, D. Morita, Y. Nozaki, A. Masuda, and H. Matsumura, J. Appl. Phys., 91 (2002) 1650.

20. P. J. S. B. Caridade, S. P. J. Rodrigues, F. Sousa, and A. J. C. Varandas, J. Phys. Chem. A, 109 (2005) 2356.

21. H. Umemoto, T. Kato, M. Takiguchi, S. Takagi, and H. Horibe, Thin Solid Films, 635 (2017) 27. 